\title{
Corrigendum: Something about the Mechanical Moment of Inertia
}

\author{
${ }^{1}$ Florian Ion T. Petrescu, ${ }^{2}$ Antonio Apicella, ${ }^{2}$ Aversa Raffaella, ${ }^{3}$ Relly Victoria Petrescu, ${ }^{4}$ John Kaiser Calautit \\ and ${ }^{5}$ Aniello Riccio \\ ${ }^{l}$ Department of Theory of Mechanisms and Robots, Bucharest Polytechnic University, Bucharest, Romania \\ ${ }^{2}$ Advanced Material Lab, Department of Architecture and Industrial Design, Second University of Naples, Aversa (CE) Italy \\ ${ }^{3}$ Department of Transport, Traffic and Logistics, Bucharest Polytechnic University, Bucharest, Romania \\ ${ }^{4}$ Department of Mechanical Engineering, University of Sheffield, Sheffield, United Kingdom \\ ${ }^{5}$ Second University of Naples, Naples, Italy
}

Correction to: American Journal of Applied Sciences

http://doi.org/10.3844/ajassp.2016.1085.1090, published online 03 November 2016;

updated 29 August 2019

The original version of this Article contained Mr. MirMilad Mirsayar as a Co-

Author. Mr. Mirsayar has not contributed to the preparation and publication of this manuscript.

These errors have now been corrected in the HTML and PDF versions of the Article. http://doi.org/10.3844/ajassp.2016.1085.1090. 